\title{
Effects of Oxygen Plasma Treatment on the Wettability of Polypropylene Fabrics
}

\author{
Young Ah Kwon \\ Dept. of Fashion Industry, Silla University; Busan, Korea
}

\begin{abstract}
The objective of this study is to give PP(polypropylene) fabric a good affinity for water. Oxygen plasma was treated to PP fabrics in a commercial glow discharge reactor with different RF power, discharge pressure, and reaction time. The PP fiber surfaces were characterized by the measurement of contact angle and ESCA. A JEOL scanning electron microscope was used to observe the surface morphology of fibers. The spontaneous water uptake amount of PP fabrics was determined by the demand wettability test. To determine the effect of aging on the surface properties of $\mathrm{O}_{2}$ plasma treated PP, all the above measurements of the samples were carried out after 1, 7, 30, 60, and 150 days. The results are as follows. The PP fiber surfaces treated by $\mathrm{O}_{2}$ plasma treatment have a chemical composition that consisted of various oxygen containing polar groups. Consequently, the contact angles of the treated PP fibers decreased, which improved the water uptake rate of PP fabrics. Surface roughness of the treated PP affected the fabric wettabiity as well. Wettability of the treated PP decreased and leveled off with aging. The $\mathrm{O}_{2}$ plasma treatment is a simple and effective method to increase the water uptake rate of PP fabrics.
\end{abstract}

Key words : oxygen plasma, polypropylene, contact angle, wettability, aging

\section{Introduction}

The advantages of a plasma treatment for polymers in general have been quite intensively studied(Lei et al., 2011; Yasuda et al., 1984). However, the use of plasma treatment applied to fabrics is limited, based on the publications appearing in literature. This may be due to the fact that fabrics are much more complicated than films(Clark et al., 1987). When the surface of the polymer is exposed to plasma, plasma functionalizing and plasma etching always coexist on the surface, which are dependent on plasma parameters(Lei et al., 2011). When increasing the plasma treatment time, the surface roughness on the polymer film continuously increased, which was associated with a depletion of the polar functional groups by ion-flux bombardment(Lei et al., 2011). Although the wettability of fibers modified by different plasmas has been studied extensively(Kan \& Yuen, 2011; Liu et al., 2013), independent control of plasma functionalizing and plasma etching to control the surface polarity and the roughness of the fabrics has been difficult to realize. Therefore, the plasma-modification mechanism for the wettability of fabrics is also not clear, because the description of the surface dynamic behavior of the modified fiber relative to surface polarity and roughness is not fully understood.

PP fibers has good tensile strength, abrasion resistance, wrinkle

$\dagger$ Corresponding author; Young Ah Kwon

Tel. +82-51-999-5063, Fax. +82-51-999-5452

E-mail: yakwon@silla.ac.kr recovery, and chemical resistance, but it has low wettability. The recently developed polypropylene fabrics knitted with hollow polypropylene fibers are suitable for the wicking materials that draw moisture away from the body. The micro surface of the PP fiber may be suitable for the quick wetting materials. The PP membranes were developed successfully bu Kosaraju and Sirkar(2008). The surface and the pore interior of PP flat sheet and hollow fiber membranes were hydrophilized first by pre-wetting with acetone followed by oxidation with chromic acid solution. Weon and Lee(2012) found that Ar-plasma treatment provides a hydrophilic state on the PP blended surface.

Glow discharge plasma treatment at low pressure has been employed to modify the surface characteristics of PP(Sarmadi et al., 1993; Tsai et al., 1997). Improved wettability and dyeability of PP fabrics were obtained using glow discharge plasma by grafting nitrogen-containing active groups on the surface(Sarmadi et al., 1993). Hydrophilic surfaces have been developed through glow discharge plasma at one-atmosphere on PP webs(Tsai et al., 1997). After atmospheric air plasma treatment, the oxygen content of the synthetic textile fibers was increased indicating that hydrophilic groups had been introduced into the fabric leading to the improved wettability(Kan \& Yuen, 2013). Although there is an abundant amount of literature on surface modification of using plasma to improve wettability of natural or synthetic fibrous materials, few in depth studies of oxygen $\left(\mathrm{O}_{2}\right)$ plasma on PP fabrics exist. The present investigation was aimed at surface modification and characterization of PP surface by $\mathrm{O}_{2}$ plasma treatment. 


\section{Methods}

\subsection{Materials}

Commercial PP plain fabric(fabric density $108 \times 104 /$ inch and fabric weight $134 \mathrm{~g} / \mathrm{m}^{2}$ ), purchased from Test Fabrics Inc. was used in all experiments. The fabric samples were Soxhlet extracted in benzene and distilled water for 4 hours each and dried under vacuum condition before use. $\mathrm{O}_{2}$ (Aldrich Chemical) was used without further purification.

\subsection{Plasma treatment}

$\mathrm{O}_{2}$ plasma treatments were carried out in a commercial installation. The apparatus include the parallel plate electrodes, a $30 \mathrm{kHz}$ RF generator, water-cooling system, a vacuum pump, pressure gauge, and gas flow meter. In a typical experiment four fabric samples $(9 \mathrm{~cm}$ in diameter) were placed on the grounded electrode. Then the system was vacuum to ground pressure level. After creating the selected gas pressure, the plasma was ignited and maintained for the desired reaction period. At the end of the irradiation, the samples were removed from the reactor and stored in Pyrex containers under constant relative humidity $(50 \%)$ and temperature $\left(27^{\circ} \mathrm{C}\right)$ conditions for 24 hours, then subjected to analytical measurements.

\subsection{ESCA}

ESCA spectra were obtained by using a Perkin-Elmer 5400 spectrometer with an $\mathrm{Ng}$ X-ray source and a data reduction system. For the elemental analysis, the pass energy of $35.73 \mathrm{eV}$ was utilized for multiple spectra analysis. The sample fabrics were cut by clean scissors and carefully mounted on the sample holder, where binding energy assignments for particular functionalities are made.

\subsection{Contact angle measurement}

The advancing contact angles of water on fiber surface were obtained by the Wilhelmy balance technique(Miller \& Young, 1975). This technique was utilized to demonstrate the effects of several treatment variables on the surface character of PP fibers. The average values o contact angles of 10 fibers from the PP fabrics.

\subsection{Surface Morphology by SEM}

A JEOL scanning electron microscope was used to observe the surface morphology of fibers. To provide conductivity for the fiber samples, a coating of gold was applied in a Gold Sputter-Etch unit. The $\mathrm{O}_{2}$ plasma-treated and untreated samples were observed at magnifications 4700 and $10000 \mathrm{X}$.

\subsection{Demand wettability test}

The effect of plasma treatment on the spontaneous water uptake amount of fabrics was determined by the demand wettability test(Miller \& Tyomkin, 1984). The demand wettability test is a sensitive gravimetric method which is capable of measuring the rate and the total amount of liquid uptake in the direction perpendicular to the plane of a fabric. The initial water uptake and the equilibrium water uptake amount of PP fabrics before and after $\mathrm{O}_{2}$ plasma treatment were measured. To determine the effect of aging on the surface properties of the plasma, all the above measurements of $\mathrm{O}_{2}$ plasma treated samples were carried out after 1, 7, 30,60, and 150 days.

\section{Results and Discussion}

\subsection{Surface modification of PP fibers}

Fig. 1 shows the $\mathrm{C}_{1 \mathrm{~s}}$ spectra of PP before and after $\mathrm{O}_{2}$ plasma exposure. The untreated $\mathrm{PP}$ exhibited a strong single carbon peak at $285 \mathrm{eV}$. The oxygen substituted $\mathrm{C}_{1 \mathrm{~s}}$ peak of the treated PP was much wider than that of the untreated PP. The $\mathrm{C}_{1 \mathrm{~s}}$ shifts between 286 and $292 \mathrm{eV}$ arise from a mixture of oxidized group. Carbon

(a)

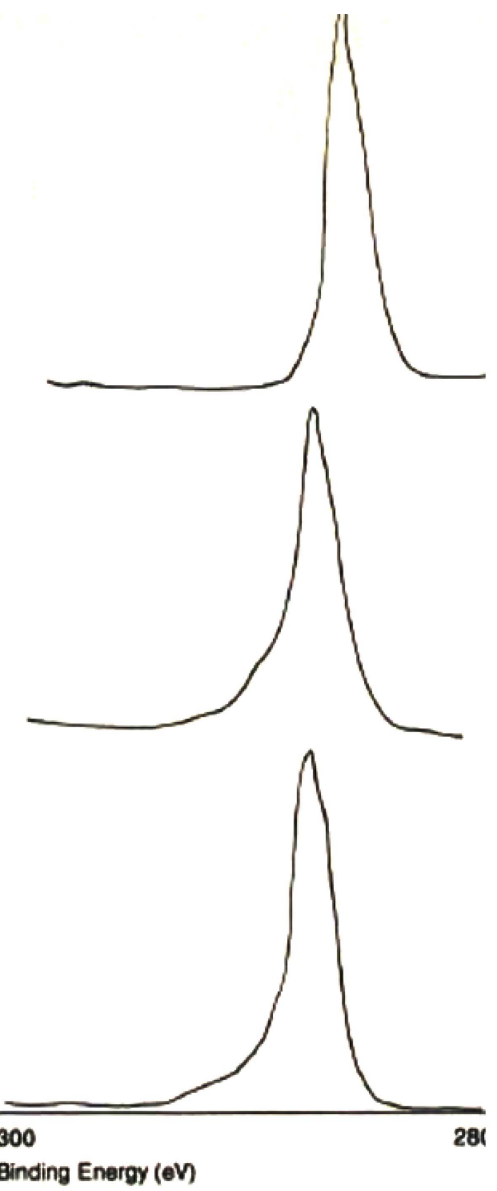

Fig. 1. $\mathrm{C}_{\mathrm{s}}$ spectra of PP fibers before and after $\mathrm{O}_{2}$ plasma $(100 \mathrm{~W}$, 200 mTorr) treatment: untreated (a); treated for $5 \mathrm{~min}$ (b); treated for 20 $\min (\mathrm{c})$. 
Table 1. Effect of $\mathrm{O}_{2}$ plasma exposure time on the surface atomic ratios of PP

\begin{tabular}{cccc}
\hline Exposure time $(\mathrm{min})$ & $\mathrm{O} / \mathrm{C}$ & $\mathrm{F}$ & $p$-value \\
\hline Untreated & $0.04 \mathrm{a}$ & & \\
5 & $0.81 \mathrm{~b}$ & 13.8 & 0.00 \\
20 & $1.65 \mathrm{c}$ & & \\
\hline
\end{tabular}

$\mathrm{O}_{2}$ plasma treatment: discharge power $100 \mathrm{~W}$, reaction pressure 200 mTorr; and 30day aged. The mean values of the same letters are not statistically different by Duncan's significant difference, $\mathrm{a}<\mathrm{b}<\mathrm{c}$.

Table 2. Effect of RF power on the surface atomic ratios of PP

\begin{tabular}{cccc}
\hline Discharge power $(\mathrm{W})$ & $\mathrm{O} / \mathrm{C}$ & $\mathrm{F}$ & p-value \\
\hline Untreated & $0.04 \mathrm{a}$ & & \\
20 & $0.11 \mathrm{~b}$ & & \\
60 & $0.17 \mathrm{c}$ & 531.7 & 0.00 \\
80 & $0.20 \mathrm{~d}$ & & \\
100 & $2.20 \mathrm{e}$ & & \\
\hline
\end{tabular}

$\mathrm{O}_{2}$ plasma treatment: 200 mTorr of reaction pressure and $30 \mathrm{~min}$ of exposure time. The mean values of the same letters are not statistically different by Duncan's significant difference, $a<b<$ c $<$ d $<$ e.

containing a single bond to oxygen, such as with alcohol or ether, could occur around 286 to $288 \mathrm{eV}$. Carbonyl carbon was around 289 to $291 \mathrm{eV}$. Fig. 2 shows the $\mathrm{O}_{1 \mathrm{~s}}$ spectra of the untreated and the $\mathrm{O}_{2}$ plasma-treated samples at 532 and $535 \mathrm{eV}$, respectively. The higher binding energy of $\mathrm{O}_{1 \mathrm{~s}}$ shift is oxygen bonded to carbon atoms.

Table 1 shows variation of the surface atomic ratios, $\mathrm{O}_{1 \mathrm{~s}} / \mathrm{C}_{1 \mathrm{~s}}$ of PP treated with different exposure time. As the exposure time increased from $5 \mathrm{~min}$. to $20 \mathrm{~min}$, the $\mathrm{O}_{1 \mathrm{~s}} / \mathrm{C}_{1 \mathrm{~s}}$ ratio significantly increased from 0.04 to 1.65 . The $\mathrm{O}_{1 \mathrm{~s}} / \mathrm{C}_{1 \mathrm{~s}}$ ratio for the specimens treated under different discharge powers $(20 \mathrm{~W}, 60 \mathrm{~W}, 80 \mathrm{~W}$ and $100 \mathrm{~W}$ ) are shown in Table 2. The discharge power increased, the $\mathrm{O}_{1 \mathrm{~s}} / \mathrm{C}_{1 \mathrm{~s}}$ ratio increased. The specimens treated at the discharge power of $100 \mathrm{~W}$ demonstrated a $5,500 \%$ higher oxygen atom content than the untreated specimens. The $\mathrm{O}_{1 \mathrm{~s}} / \mathrm{C}_{1 \mathrm{~s}}$ ratio increased also as reaction pressure from $100 \mathrm{mTorr}$ to $200 \mathrm{mTorr}$ increased. The Table 3 indicates that the ratio of $\mathrm{O}_{1 \mathrm{~s}} / \mathrm{C}_{1 \mathrm{~s}}$ is 1.71 for the PP treated at $100 \mathrm{~m}$ Torr and 2.20 for the PP treated at 200 mTorr.

Table 3. Effect of reaction pressure on the surface atomic ratios of PP

\begin{tabular}{cccc}
\hline Reaction pressure (mTorr) & $\mathrm{O} / \mathrm{C}$ & $\mathrm{F}$ & $p$-value \\
\hline Untreated & $0.04 \mathrm{a}$ & & \\
100 & $1.71 \mathrm{~b}$ & & \\
175 & $2.16 \mathrm{c}$ & 909.5 & 0.00 \\
200 & $2.20 \mathrm{~d}$ & & \\
\hline
\end{tabular}

$\mathrm{O}_{2}$ plasma treatment: discharge power $100 \mathrm{~W}$ and exposure time $30 \mathrm{~min}$. The mean values of the same letters are not statistically different by Duncan's significant difference, $\mathrm{a}<\mathrm{b}<\mathrm{c}<\mathrm{d}$.

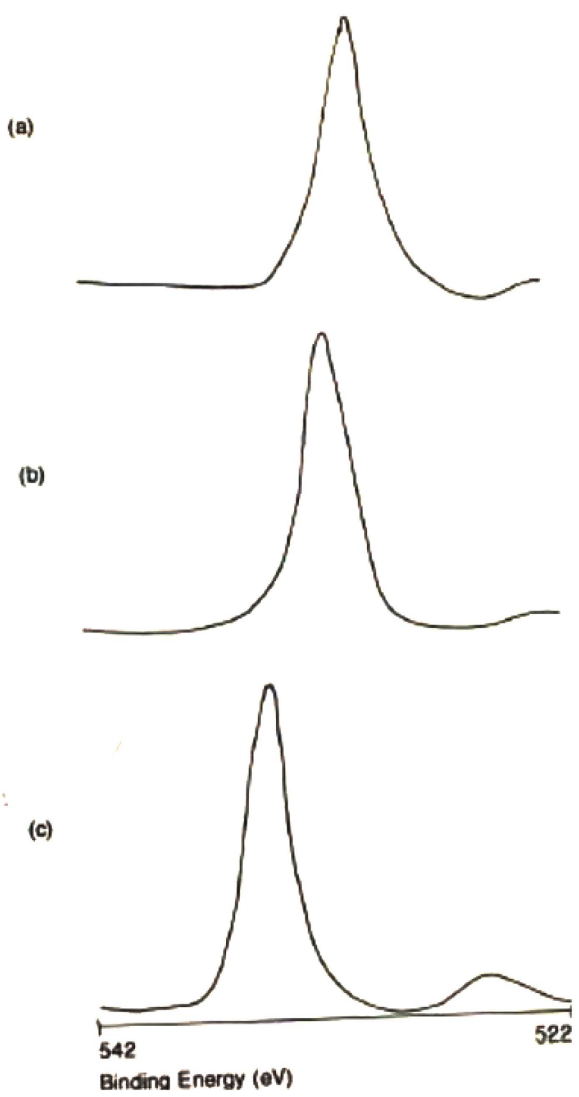

Fig. 2. $\mathrm{O}_{1 \mathrm{~s}}$ spectra of the PP fibers before and after $\mathrm{O}_{2}$ plasma treatment $(100 \mathrm{~W}, 200 \mathrm{mTorr})$ : untreated (a), treated for $5 \mathrm{~min}(\mathrm{~b})$, and treated for $20 \min (\mathrm{c})$.

\subsection{Contact angles of PP fibers}

The decreased contact angles of all the treated PP fibers indicates more hydrophilic surfaces generated by $\mathrm{O}_{2}$ plasma. The $\mathrm{O}_{2}$ plasma treatment improved hydrophilic properties of PP fibers. The water contact angles of PP fibers decreased with increasing discharge power, as shown in Fig. 3. The contact angle of PP fibers decreased from $82^{\circ}$ up to $65^{\circ}$ with increasing discharge pressure, as sown in Fig. 4. Fig. 5 shows the water contact angles for the $\mathrm{O}_{2}$ plasmatreated PP fibers that were aged for 1, 7, 30, 60, and 150 days. ESCA analysis showed that the fiber surfaces treated in the $\mathrm{O}_{2}$ plasma system have a chemical composition that consisted of various oxygen containing polar groups even after 150 days of aging. Therefore. the contact angles of PP fiber were still significantly lower than those of the untreated PP fiber even after 150 days of aging. Long-term stability of polar groups was important for creating durable water wetting. Wettability decreases and levels off with aging because the $\mathrm{O}_{2}$ plasma-treated PP fiber is depolarized with time, and the polar groups stay without reversible reaction. 


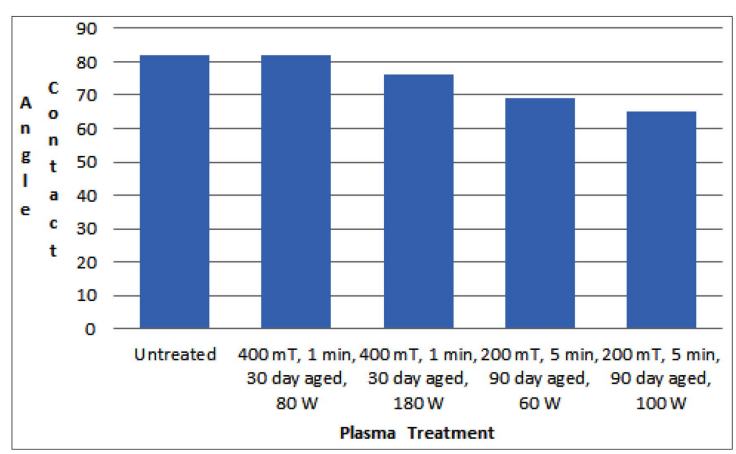

Fig. 3. Effect of RF power on the water contact angles of PP fibers.

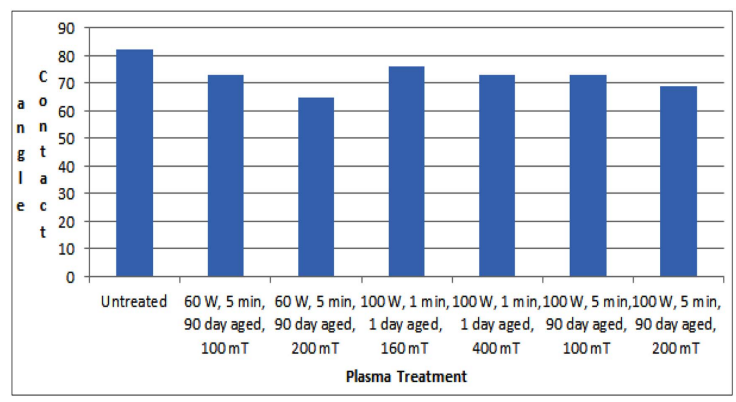

Fig. 4. Effect of Reaction Pressure on the water contact angles of PP fibers.

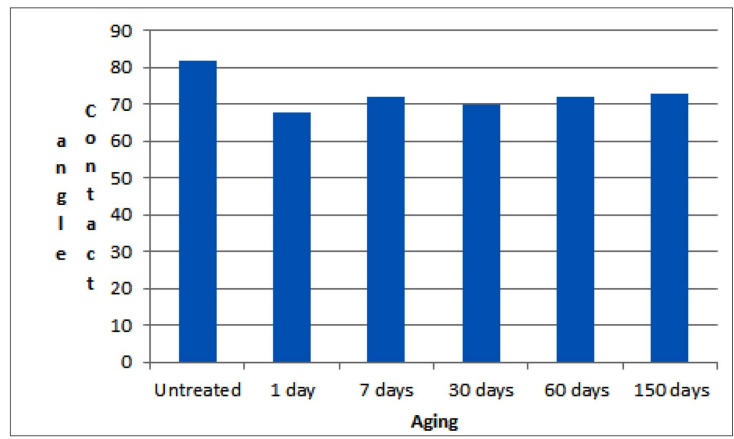

Fig. 5. Effect of aging on the water contact angles of PP fibers. $\mathrm{O}_{2}$ plasma treatment: discharge power $100 \mathrm{~W}$, discharge pressure, $200 \mathrm{mTorr}$, and exposure time $30 \mathrm{~min}$.

\subsection{Wettability of PP fabrics}

Table 4 shows the effect of the $\mathrm{O}_{2}$ plasma treatments on the spontaneous water uptake of PP fabrics. For this experiment, samples were discharged at a pressure of 200 mTorr and exposure duration of $1 \mathrm{~min}$. Increasing the discharge power up to $180 \mathrm{~W}$ and keeping all other conditions constant gradually increased the initial water uptake amount. The fiber surface chemical composition might affect the rate of water uptake of PP fabrics. It is believed that functional groups like carbonyl group, hydroxyl group and carboxyl
Table 4. Effect of discharge power on the water uptake amount of the $\mathrm{O}_{2}$ plasma-treated PP fabrics

\begin{tabular}{cccc}
\hline Power & \multicolumn{3}{c}{ Water uptake amount $\left(\mathrm{mg} / \mathrm{cm}^{2}\right)$} \\
\cline { 2 - 4 } level (W) & $5 \mathrm{sec}$. & $300 \mathrm{sec}$. & $600 \mathrm{sec}$. \\
\hline Untreated & $1.2 \mathrm{a}$ & $40.8 \mathrm{~d}$ & $44.0 \mathrm{~d}$ \\
20 & $5.5 \mathrm{~b}$ & $33.3 \mathrm{a}, \mathrm{b}$ & $33.9 \mathrm{a}, \mathrm{b}, \mathrm{c}$ \\
40 & $6.5 \mathrm{c}$ & $34.1 \mathrm{a}, \mathrm{b}$ & $34.9 \mathrm{~b}, \mathrm{c}$ \\
60 & $6.4 \mathrm{c}$ & $34.7 \mathrm{a}, \mathrm{b}$ & $35.1 \mathrm{~b}, \mathrm{c}$ \\
80 & $6.5 \mathrm{c}$ & $32.2 \mathrm{a}$ & $32.5 \mathrm{a}$ \\
120 & $6.3 \mathrm{c}$ & $32.9 \mathrm{a}$ & $33.5 \mathrm{a}, \mathrm{b}$ \\
180 & $6.9 \mathrm{~d}$ & $36.8 \mathrm{c}$ & $37.3 \mathrm{c}$ \\
\hline
\end{tabular}

$\mathrm{O}_{2}$ plasma treatment: reaction pressure $200 \mathrm{mTorr}$ and exposure time 30 $\mathrm{min}$. The mean values of the same letters are not statistically different by Duncan's significant difference, $\mathrm{a}<\mathrm{b}<\mathrm{c}<\mathrm{d}$.

Table 5. Effect of discharge pressure on the water uptake amount of the $\mathrm{O}_{2}$ plasma-treated $\mathrm{PP}$ fabrics

\begin{tabular}{clcc}
\hline \multirow{2}{*}{$\begin{array}{c}\text { Pressure level } \\
\text { (mTorr) }\end{array}$} & \multicolumn{3}{c}{ Water uptake amount $\left(\mathrm{mg} / \mathrm{cm}^{2}\right)$} \\
\cline { 2 - 4 } & $5 \mathrm{sec}$. & $300 \mathrm{sec}$. & $600 \mathrm{sec}$. \\
\hline Untreated & $1.2 \mathrm{a}$ & $40.8 \mathrm{~d}$ & $44.0 \mathrm{~d}$ \\
100 & $3.1 \mathrm{~b}$ & $30.3 \mathrm{a}$ & $32.2 \mathrm{a}$ \\
150 & $6.9 \mathrm{c}$ & $35.9 \mathrm{c}$ & $38.1 \mathrm{c}$ \\
175 & $8.0 \mathrm{c}$ & $34.9 \mathrm{~b}, \mathrm{c}$ & $41.4 \mathrm{c}$ \\
200 & $12.2 \mathrm{c}$ & $35.9 \mathrm{c}$ & $36.5 \mathrm{~b}, \mathrm{c}$ \\
250 & $7.5 \mathrm{c}, \mathrm{d}$ & $31.3 \mathrm{a}, \mathrm{b}$ & $33.0 \mathrm{a}$ \\
\hline
\end{tabular}

$\mathrm{O}_{2}$ plasma treatment: discharge power $100 \mathrm{~W}$ and exposure time $30 \mathrm{~min}$. The mean values of the same letters are not statistically different by Duncan's significant difference, $\mathrm{a}<\mathrm{b}<\mathrm{c}<\mathrm{d}$.

group were formed after the $\mathrm{O}_{2}$ plasma treatment, leading to hydrophilic surface of polypropylene fabrics. Apart from formation of polar groups, the plasma etching effect enhancing the capillary flow was another reason causing improved wettability.

The results of demand wettability test indicate that efficiency of the hydrophilic modification was also dependent on the discharge pressure. Table 5 shows that with increasing discharge pressure from 100 to $5 \mathrm{mTorr}$. The initial water uptake amount increased from 3.1 to $12.2 \mathrm{mg} / \mathrm{cm}^{2}$, while the total water uptake amount increased from 32.2 to $36.5 \mathrm{mg} / \mathrm{cm}^{2}$. Several aspects affect the total water uptake amount of fabrics, such as pore size, fiber surface roughness, and fiber surface chemical composition.

Surface roughness of the plasma-treated PP fiber appears in the SEM photographs. Fig. 6 represents the surfaces of the untreated and plasma-treated PP fibers. The $\mathrm{O}_{2}$ plasma-treatment resulted micro etchings on the PP surface. The width of etch units was 50 to $100 \AA$ and the space of the units were 400 to $800 \AA$ The fold width in polymer single crystals was known to be on the order of $100 \AA$ and was considerably consistent to the width of the etch units exposed PP fiber treated by $\mathrm{O}_{2}$ plasma. The depth of ridges increased with increasing discharge pressure. The ridged structure was the accretion of continuous cavities by the removal of the 


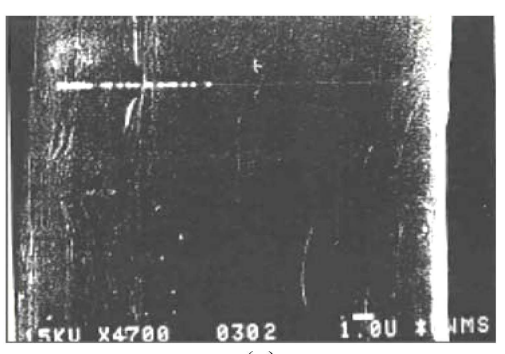

(a)

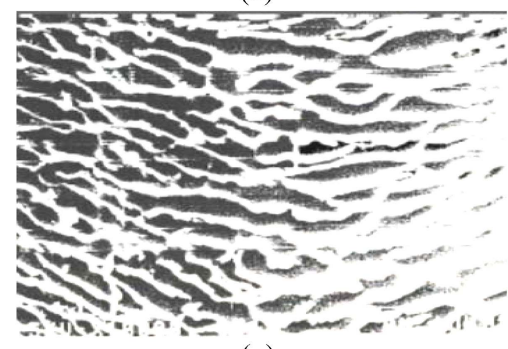

(c)

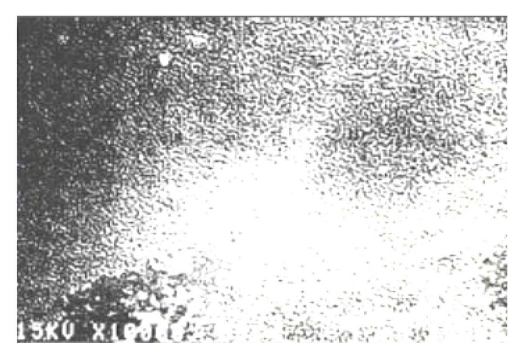

(b)

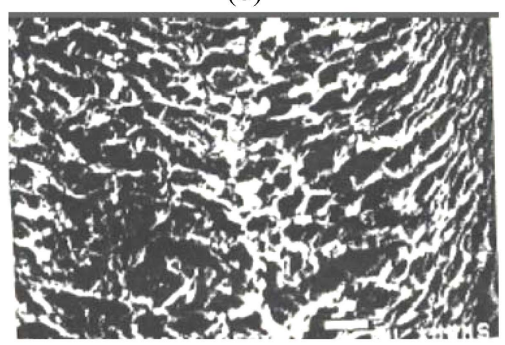

(d)

Fig. 6. SEM photographs of PP fibers: untreated (a) and $\mathrm{O}_{2}$ plasma-treated with discharge power of $100 \mathrm{~W}$ for 30 min at different discharge pressure of; (b) $100 \mathrm{mTorr}$, (c) $175 \mathrm{mTorr}$, and (d) $250 \mathrm{mTorr}$.

amorphous chain segments. This greater depth of ridge corresponded to a faster initial water uptake rates and a lower total water uptake amount. The initial water uptake rate is faster with increased dischared pressure or discharge power. The main reason for the improvement in the spontaneous water uptake rate of the fabric was the introduction of hydrophilic functional groups on the surface of PP fibers and it may might also attributed to the oxygen plasma etching effect on the fiber surface which increasesd surface area of the fiber and enhancesd the capillary effect to transport the liquid(Kan \& Yueen, 2013). The $\mathrm{O}_{2}$ plasma etching was a physical removing process on the surface of the PP fibers leading to surface roughening. It is suggested that the formation of functional groups containing oxygen was the main reaction on the surface of plasmamodified PP samples treated with 100 mTorr of discharge pressrueeure, whereas the depletion of the polar functional groups car-

Table 6. Effect of aging on the water uptake amount of the $\mathrm{O}_{2}$ plasmatreated PP fabrics

\begin{tabular}{cccc}
\hline \multirow{2}{*}{$\begin{array}{c}\text { Aging } \\
\text { time (day) }\end{array}$} & \multicolumn{3}{c}{ Water uptake amount $\left(\mathrm{mg} / \mathrm{cm}^{2}\right)$} \\
\cline { 2 - 4 } & $5 \mathrm{sec}$ & $300 \mathrm{sec}$. & $600 \mathrm{sec}$. \\
\hline Untreated & $1.21 \mathrm{a}$ & $40.8 \mathrm{~d}$ & $44.0 \mathrm{~d}$ \\
1 & $5.45 \mathrm{~b}$ & $33.3 \mathrm{a}, \mathrm{b}$ & $33.9 \mathrm{a}, \mathrm{b}, \mathrm{c}$ \\
7 & $6.55 \mathrm{c}$ & $34.1 \mathrm{a}, \mathrm{b}$ & $34.9 \mathrm{~b}, \mathrm{c}$ \\
30 & $6.42 \mathrm{c}$ & $34.7 \mathrm{a}, \mathrm{b}$ & $35.1 \mathrm{~b}, \mathrm{c}$ \\
60 & $6.56 \mathrm{c}$ & $32.2 \mathrm{a}$ & $32.5 \mathrm{a}$ \\
\hline
\end{tabular}

$\mathrm{O}_{2}$ plasma treatment: discharge power $100 \mathrm{~W}$, discharge pressure $200 \mathrm{mTorr}$, and exposure time $30 \mathrm{~min}$. The mean values of the same letters are not statistically different by Duncan's significant difference, $\mathrm{a}<\mathrm{b}<\mathrm{c}<\mathrm{d}$. ried out due to plasma etching above 175 mTorr of discharge pressrueeure is associated with the increase of surface roughness.

The effect of aging on the spontaneous water uptake of PP fabrics was also investigated, and the results are shown in Table 6. The wettability decay began to level off after treatment for 7 days. We found that the wettable PP fabrics even after more than a year. After 7 days of aging, there was a significant amount of oxygen atoms on fiber surface, which contributed to low contact angle, resulting in a wettable surface.

\section{Conclusions}

This paper presents a way of improving wettability of PP fabrics by $\mathrm{O}_{2}$ plasma treatment. The surface properties of PP fibers and the dem and wettability of PP fabrics were compared before and after plasma treatment. The results show the oxidized PP fiber surface affects fiber surface wettability because it determines the surface bonding forces with water. The formation of the polar functional groups containing oxygen, not only depends on the oxygen plasma density, but also on the oxygen ion-flux energy. When increasing the treatment time, the surface roughness on the PP continuously increases, which is associated with a depletion of the polar functional groups by ion-flux bombardment. Surface roughness of the plasma-treated PP fiber appears in the SEM photo graphs. These surfaces roughness may affect the fabric wettabiity as well. Wettability decreases and levels off with aging because the fiber is depolarized with time, and the polar groups stay without reversible 
reaction.

The polar functional groups on the surface of the plasma-treated PP fiber increase the spontaneous water uptake rate. $\mathrm{O}_{2}$ plasmatreatment controlling plasma reaction pressure is probably a simple and effective method to further improve the spontaneous wettability of the plain PP fabrics.

\section{References}

Clark, D. T., Dilks, A., \& Shuttleworth, D. (1987). The application of plasmas to the synthesis and surface modification of polymers. Chapter 9, University of Durham.

Kan, C. W., \& Yuen, C. W. M. (2013). Effect of atmospheric pressure plasma treatment on wettability and dryability of synthetic textile fibre. Surface and Coatings Technology, 228, 607-610.

Kosaraju, P. B., \& Sirkar, K. K. (2008). Interfacially polymerized thin film composite membranes on microporous polypropylene supports for solvent-resistant nanofiltration. Journal of Membrane Science, $321(2), 155-161$

Lei, M. K., Liu, Y., \& Li, Y. P. (2011). Controllable wettability of poly(ethylene terephthlate) film modified by oxygen combined inductively and capacitively coupled radio-frequency plasma.
Applied Surface Science, 257(16), 7350-7358.

Liu, Z., Chen, P., Han, D., Lu, F., Yu, Q., \& Ding, Z. (2013). Atmospheric air plasma treated PBO fibers: Wettability, adhesion and aging behaviors. Vacuum, 92, 13-19.

Miller, B., \& Tyomkin, I. (1984). Spontaneous transplanar uptake of liquids by fabrics. Textile Research Journal, 54, 706-712.

Miller, B., \& Young, R. A. (1975). Methodology for studying the wettability of filament. Textile Research Journal, 45, 359-365.

Sarmadi, A. M., Ying, T. H., \& Denes, F. (1993). Surface modification of polypropylene fabrics by acrylonitrile cold plasma. Textile Research Journal, 63(12), 697-705.

Tsai, P. P., Wadsworth, L. C., \& Roth, J. R. (1997). Surface modification of fabric using a one-atmosphere glow discharge plasma to improve fabric wettability. Textile Research Journal, 67(5), 359-369.

Weon, J. I., \& Lee, S. Y. (2012). Improvement of wettability and removal of skin layer on ar-plasma-treated polypropylene blend surface. Polymer, 36(4), 461-469.

Yasuda, T., Gazicki, M., \& Yasuda. G. H. (1984). Effects of glow discharge on fibers and fabrics. Journal of Applied Polymer science: Applied Polymer symposium, 38, 201-214.

(Received 22 January 2014; 1st Revised 11 February 2014; 2nd Revised 18 February 2014; Accepted 2 May 2014)

Copyright (c) 2014 (by) the authors. This article is an open access article distributed under the terms and conditions of the Creative Commons Attribution license (http://creativecommons.org/licenses/by/3.0/), which permits unrestricted use, distribution, and reproduction in any medium, provided the original work is properly cited. 